\title{
Iron is prioritized to red blood cells over the brain in phlebotomized anemic newborn lambs
}

\author{
Tara G Zamora ${ }^{1,2}$, Sixto F Guiang 3rd ${ }^{2}$, John A Widness ${ }^{3}$ and Michael K Georgieff ${ }^{2}$
}

BACKGROUND: Critically ill preterm and term neonates are at high risk for negative iron balance due to phlebotomy that occurs with frequent laboratory monitoring, and the high iron demand of rapid growth. Understanding the prioritization of iron between red blood cells (RBCs) and brain is important given iron's role in neurodevelopment.

METHODS: Ten neonatal twin lamb pairs $(n=20)$ underwent regular phlebotomy for $11 \mathrm{~d}$. Lambs were randomized to receive no iron or i.v. daily iron supplementation from 1 to $5 \mathrm{mg} / \mathrm{kg}$. Serum hemoglobin concentration and reticulocyte count were assayed, iron balance calculated, and iron content of RBCs, liver, brain, muscle, and heart measured at autopsy.

RESULTS: Among phlebotomized lambs: (i) liver iron concentration was directly related to net iron balance $(r=0.87$; $P<0.001$ ) and (ii) brain iron concentration was reduced as a function of net iron balance $(r=0.63)$ only after liver iron was depleted. In animals with negative iron balance, total RBC iron was maintained while brain iron concentration decreased as a percentage of the iron present in $\mathrm{RBCs}(r=-0.70 ; P<0.01)$ and as a function of reticulocyte count $(r=-0.63 ; P<0.05)$.

CONCLUSION: Phlebotomy-induced negative iron balance limits iron availability to the developing brain.

\section{INTRODUCTION}

Anemia of prematurity is exacerbated by phlebotomy-induced anemia (PIA). Preterm and critically ill term neonates are at high risk of anemia due to frequent blood sampling needed for laboratory analysis, often totaling $10-40 \mathrm{ml} / \mathrm{kg}$ per week (1). The negative iron balance created by PIA has the potential for being a major neurodevelopmental risk factor for high-risk neonates. In support of this speculation, disrupted learning and memory behavior and slower speed of processing have been demonstrated in iron-deficient neonates $(2,3)$ and in preclinical models of neonatal brain iron deficiency (4-6).

The degree of anemia that can be tolerated in a preterm neonate is not known. Two recent randomized controlled trials, the PINT trial and the Iowa trial, examined the effect of liberal vs. restrictive transfusion practices in the neonatal intensive care unit. These trials examined transfusion triggers ranging from 70 to $150 \mathrm{~g} / \mathrm{l}$ that varied based on the infant's chronological age and respiratory support needs. Findings from these two trials remain inconclusive, yielding conflicting results between the short-term and long-term neurodevelopmental follow-up data $(7-10)$. However, with greater awareness of the potential risks associated with RBC transfusions, there has been a general trend in clinical practice toward limiting transfusions and tolerating lower hemoglobin concentrations through strict protocols (11). Tolerance of greater degrees of anemia and provision of less RBC transfusions potentially negatively affects the total body iron status, placing ill term and preterm infants at increased risk of brain iron deficiency and neurodevelopmental sequelae. This situation is complicated by iron status being traditionally measured clinically by biomarkers of active erythropoiesis such as reticulocyte count, or red cell iron status based on hemoglobin, mean corpuscular volume, or zinc protoporphryn concentrations (12). The validity of these biomarkers to index the iron status on the brain and thus the risk for neurodevelopmental sequelae depends on the assumption that iron is depleted and repleted in the brain concurrently with the RBCs. However, autopsy studies of growth-restricted infants and infants of diabetic mothers have demonstrated brain iron deficiency in the absence of anemia $(13,14)$, suggesting that the iron status of the brain and the peripheral blood are not mirror images. Therefore, if brain iron is potentially compromised at the expense of maintaining RBC iron status, the strategy of screening for brain iron deficiency with tools utilizing RBC iron markers will not be accurate, and in fact, may be misleading.

The conflicting clinical data regarding RBC transfusion thresholds (7-10) along with the autopsy findings from other at-risk infants $(13,14)$ suggest complex mechanisms leading to brain iron deficiency not easily predictable based on traditional peripheral blood measures of anemia and RBC activity. The aim of this study was to examine the relationship and prioritization of iron between two important iron-dependent developmental processes, erythropoiesis and brain development. We used PIA and variable iron supplementation in the newborn lamb to generate a broad spectrum of iron balance that included near-complete depletion of iron stores. Significant negative iron balance was induced to place the brain in direct 
competition with the RBCs for remaining available iron. We hypothesized that brain iron status would be compromised at the expense of continued erythropoiesis in the phlebotomized neonatal lamb.

\section{RESULTS}

The net iron balance of all iron-treated groups differed significantly $(P<0.01)$ compared to the phlebotomized group that received $0 \mathrm{mg} / \mathrm{kg} / \mathrm{d}$. Higher doses of supplemental iron resulted in increasingly positive net iron balance (Figure 1). Mean negative iron balance occurred in the 0 and $1 \mathrm{mg} / \mathrm{kg} / \mathrm{d}$ iron-treated group. All animals in both groups were in negative balance. The $2 \mathrm{mg} / \mathrm{kg} / \mathrm{d}$ group achieved a net neutral iron balance. Positive iron balance was present at daily doses of $5 \mathrm{mg} / \mathrm{kg} / \mathrm{d}$ of i.v. iron supplementation in phlebotomized animals and in non-phlebotomized control animals receiving $3 \mathrm{mg} / \mathrm{kg} / \mathrm{d}$ iron supplementation. These changes in iron balance were reflected by a similar change in iron indices over the phlebotomy period (Table 1). Plasma iron was low, total ironbinding capacity (TIBC) high, and TIBC saturation low in the 0 and $1 \mathrm{mg} / \mathrm{kg} / \mathrm{d}$ groups in negative iron balance $(P<0.05)$. No significant change was seen in the iron indices among the $2 \mathrm{mg} / \mathrm{kg} / \mathrm{d}$ group in net neutral iron balance, and the $5 \mathrm{mg} / \mathrm{kg} / \mathrm{d}$ iron-supplemented group in positive iron balance showed a significant increase in plasma iron and TIBC saturation consistent with iron accretion $(P<0.05)$. Figure 2 shows the mean hemoglobin in each group prior to exchange transfusion (day

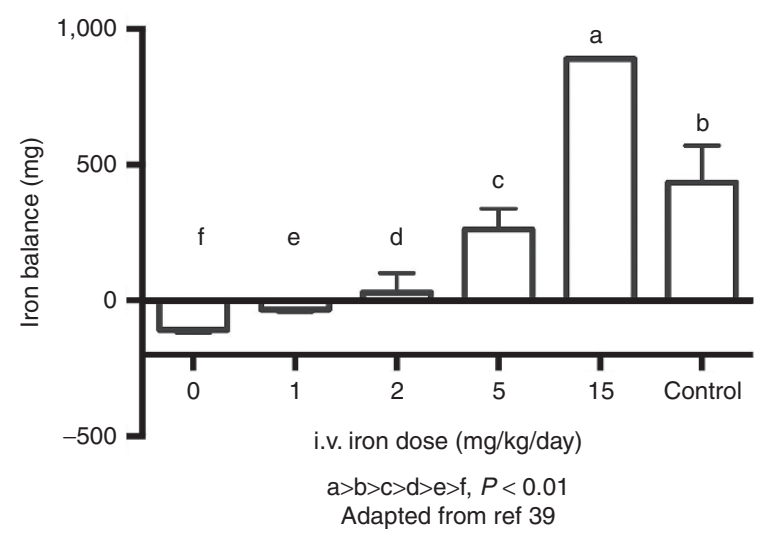

Figure 1. Net iron balance in phlebotomized, nonsupplemented lambs, phlebotomized lambs receiving varying amounts of i.v. iron supplementation, and the control group consisting of nonphlebotomized lambs receiving an average daily dose of $3 \mathrm{mg} / \mathrm{kg} / \mathrm{d}$ of i.v. iron supplementation is shown $(a>b>c>d>e>f ; P<0.01)$. Values are mean \pm SEM.
1), after exchange transfusion (day 2), and at sacrifice (days $11-12)$. Only the animals in positive iron balance $(5 \mathrm{mg} / \mathrm{kg} / \mathrm{d}$ group) showed an increase in mean hemoglobin over the phlebotomy period. The 10 lambs receiving no iron gained weight slower than their 10 twin siblings that received iron (mean \pm SD: $42.3 \pm 5.6$ vs. $47.8 \pm 8.3 \mathrm{~g} / \mathrm{kg}$ body weight per day; $P=0.004)$, resulting in less expansion of their calculated blood volumes (mean \pm SD: $254 \pm 48$ vs. $288 \pm 68 \mathrm{ml}$ ).

As the net iron balance decreased, RBC and brain iron were preferentially maintained over liver iron. Progressively negative iron balance was directly and linearly associated with a lower percent of calculated total body iron located in the liver (Figure 3a), but a higher percentage in the RBCs (Figure 3b) and the brain (Figure 3c).

Brain iron concentration was curvilinearly related to liver iron concentration (Figure 4) with an apparent threshold liver iron concentration at which point brain iron concentration was compromised. No linear relationship was found between brain iron concentration and liver iron concentration in subjects whose liver iron concentrations were above $(r=0.24$; $P=0.65)$ the identified threshold point. Below the threshold point, the relationship between brain iron concentration and liver iron concentration was nearly linear $(r=0.54 ; P=0.06)$. This decline in brain iron concentration occurred in animals whose liver iron concentrations were $<10 \%$ of non-phlebotomized, iron-supplemented control animals. All animals in the 0 and $1 \mathrm{mg} / \mathrm{kg}$ dosage groups $(n=13)$, or those animals in negative iron balance, had liver iron concentrations $<10 \%$ of non-phlebotomized controls.

Brain iron concentration was inversely related to the percentage of total body iron in RBCs in the 13 animals in the 0 or $1 \mathrm{mg} / \mathrm{kg}$ dosage groups (Figure 5), but this relationship was not seen in those animals in neutral or positive iron balance. The findings indicate a preservation of iron delivery to $\mathrm{RBCs}$ at the expense of brain iron concentration. In the animals in negative iron balance, brain iron concentration was also inversely related to the mean percentage of reticulocytes in the peripheral blood, indicating that the prioritization of iron was occurring in the face of ongoing RBC production and contributing to brain iron deficiency (Figure 6).

\section{DISCUSSION}

Brain development and erythropoiesis are both high-priority, iron-dependent processes in the neonate. This study illustrates the biologic principle that when iron supply does not meet

Table 1. Plasma iron, TIBC, and $\%$ TIBC saturation on days 1 and 10 among the various iron dosage groups (data presented as mean \pm SEM)

\begin{tabular}{|c|c|c|c|c|c|c|c|c|c|}
\hline \multirow{2}{*}{$\begin{array}{l}\text { Iron dose } \\
(\mathrm{mg} / \mathrm{kg} / \mathrm{d})\end{array}$} & \multicolumn{3}{|c|}{ Plasma iron ( $\mu \mathrm{g} / \mathrm{dl})$} & \multicolumn{3}{|c|}{$\operatorname{TIBC}(\mu \mathrm{g} / \mathrm{dl})$} & \multicolumn{3}{|c|}{ TIBC saturation (\%) } \\
\hline & Day 1 & Day 10 & $P$ value & Day 1 & Day 10 & $P$ value & Day 1 & Day 10 & $P$ value \\
\hline 0 & $93 \pm 17$ & $8 \pm 2$ & $<0.001$ & $275 \pm 17$ & $580 \pm 26$ & $<0.001$ & $35.8 \pm 5.8$ & $1.3 \pm 0.4$ & $<0.001$ \\
\hline 2 & $99 \pm 29$ & $129 \pm 61$ & 0.43 & $278 \pm 11$ & $419 \pm 52$ & 0.15 & $34.7 \pm 9.9$ & $35.7 \pm 16.9$ & 0.95 \\
\hline 5 & $102 \pm 26$ & $203 \pm 47$ & 0.04 & $266 \pm 27$ & $393 \pm 19$ & 0.01 & $41.3 \pm 14.8$ & $52.3 \pm 14.1$ & 0.01 \\
\hline
\end{tabular}

TIBC, total iron-binding capacity. 


\section{Articles | Zamora et al.}

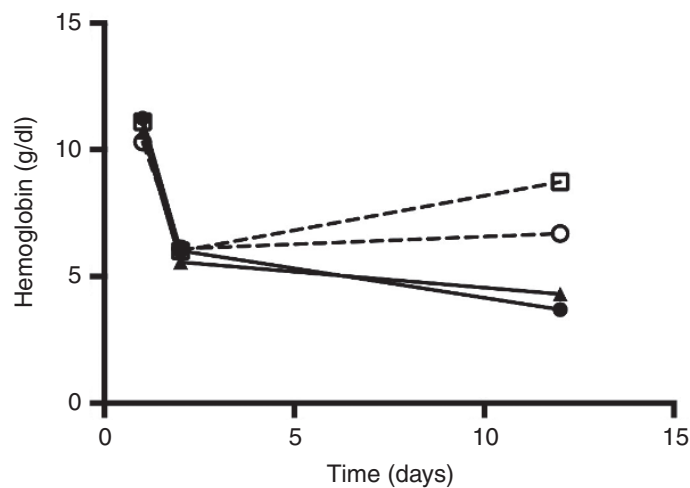

Figure 2. Mean hemoglobin concentration values of phlebotomized lambs by i.v. iron supplementation group over the phlebotomy period are shown. Initial drop in hemoglobin represents the early exchange transfusion, with ongoing phlebotomy until sacrifice by day 12 . Solid circle $=0 \mathrm{mg} / \mathrm{kg}$, solid triangle $=1 \mathrm{mg} / \mathrm{kg}$, open circle $=2 \mathrm{mg} / \mathrm{kg}$, open square $=$ $5 \mathrm{mg} / \mathrm{kg}$.

iron demand, iron is prioritized to the red blood cells over the brain, a process that could lead to brain iron deficiency as a result of neonatal phlebotomy. In humans and multiple animal models, neonatal brain iron deficiency is a risk factor for abnormal neurodevelopment (3-7). Because erythropoiesis continues in the face of limited iron availability for brain development, screening for iron deficiency by measuring hemoglobin concentrations or reticulocyte counts may fail to identify individuals at risk for impaired neurodevelopmental outcomes due to negative iron balance.

The neonatal period is a time of rapid body and brain growth and development. The neonatal brain consumes $60 \%$ of the total body oxygen consumption (15). Perinatal iron uptake and utilization is particularly active in order to support the brisk neurogenesis, synaptogenesis, dendrite formation, and myelination that define this critical developmental period (16). If iron supply is inadequate, brain iron deficiency results, which is associated with acute and persistent deficits in neural speed of processing and learning and in memory behavior $(2,3,17)$

The brain's overall high metabolic rate requires an adequate supply of iron to support synthesis of cytochromes and other iron-dependent hemoproteins, and the demand for iron increases during development since the metabolic activity of the brain is higher at that time compared to adulthood $(18-21,22)$. The elevated cytochrome c oxidase activity and ATP utilization of the neonatal brain demonstrates the importance of providing adequate iron to support its metabolic rate (23-27).

Our study shows that the erythron outcompete the other tissues, including the brain, for limited circulating iron. We have previously shown that iron allocation favors oxygen delivery over energy production. In the infant of the diabetic mother, hemoglobin production is favored over liver and brain iron (13). In fetal sheep, heart myoglobin concentrations are preserved at the expense of cytochrome $c$ concentrations during myocardial iron deficiency (28). At the cellular level, the mechanism to accomplish this inter-organ iron prioritization is unknown but may involved increased TfR-1 expression on a

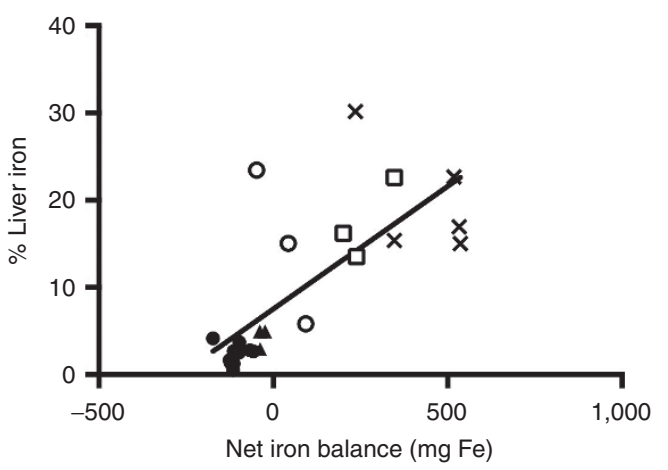

b

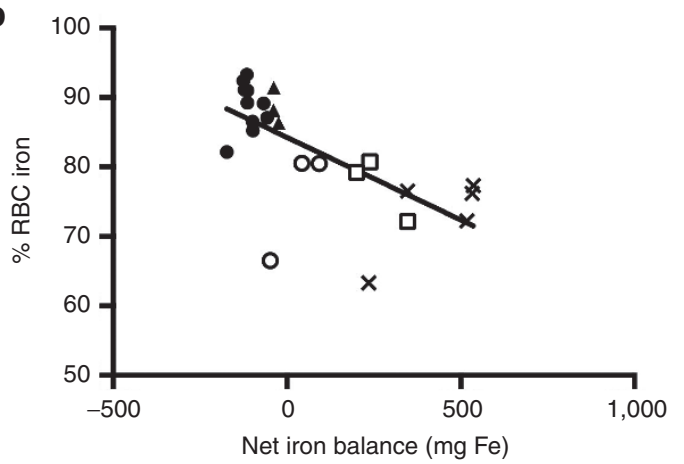

c

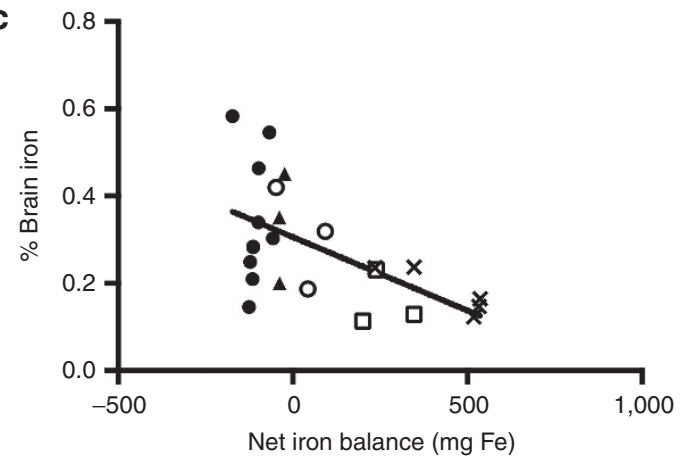

Figure 3. The distribution of total body iron in all phlebotomized as well as non-phlebotomized control lambs are shown. Percents of total body iron located within the (a) liver $(R=0.82 ; P<0.01)$, (b) $\operatorname{RBC}(R=0.76$; $P<0.01)$, and (c) brain $(R=0.64 ; P<0.01)$ are shown as a function of the net iron balance. Solid circle $=0 \mathrm{mg} / \mathrm{kg}$, solid triangle $=1 \mathrm{mg} / \mathrm{kg}$, open circle $=2 \mathrm{mg} / \mathrm{kg}$, open square $=5 \mathrm{mg} / \mathrm{kg}, X=$ control.

red cell precursors in the bone marrow and a relative reduction of the TfR-1 expression of the brain. An additional contributing factor in the inter-organ allocation of iron may be related to iron's role in brain metabolism. The mammalian target of rapamycin (mTOR) pathway is a highly conserved protein kinase intracellular signaling pathway that relies on adequate metabolic substrates, including iron and oxygen, to regulate important neuronal cell functions including cell size and survival and actin polymerization $(29,30)$. A microarray analysis published in 2007 by Carlson et al. (30) showed that neonatal iron deficiency anemia suppressed mTOR pathway activity in the rat brain. We speculate that in the current study, severe PIA may slow brain metabolism, thus decreasing brain iron demand and permitting a greater amount of the limited circulating iron to support active hematopoiesis. 


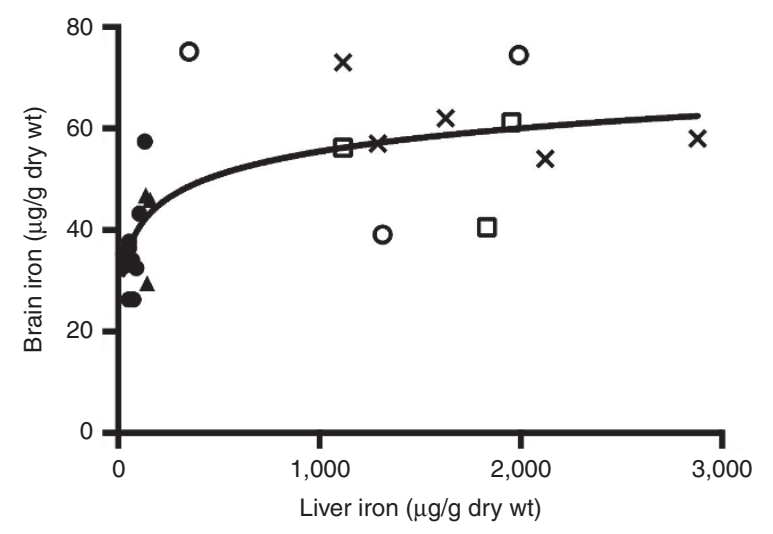

Figure 4. Brain iron concentration as a function of liver iron concentration in phlebotomized lambs and in non-phlebotomized iron-supplemented control lambs is shown. Solid circle $=0 \mathrm{mg} / \mathrm{kg}$, solid triangle $=1 \mathrm{mg} / \mathrm{kg}$, open circle $=2 \mathrm{mg} / \mathrm{kg}$, open square $=5 \mathrm{mg} / \mathrm{kg}, X=$ control.

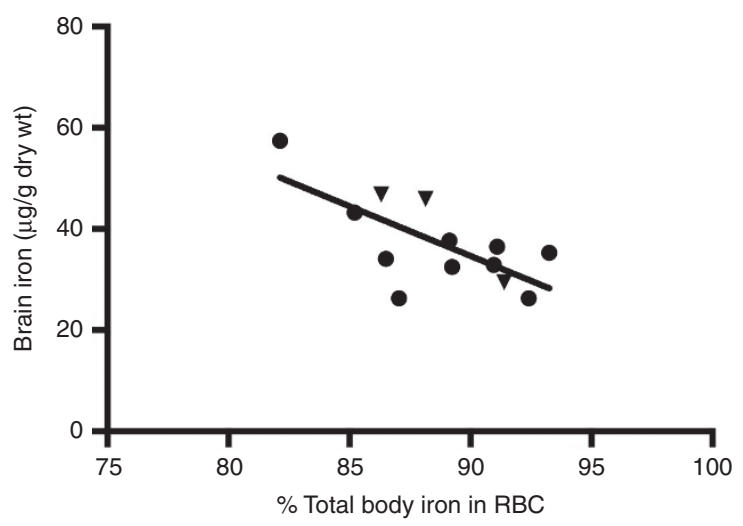

Figure 5. Brain iron concentration as a function of the percent of total measured iron found in RBCs in the two groups with net negative total body iron balance $(n=13 ; R=0.70 ; P<0.01)$. This relationship was not present in animals in net positive iron balance $(n=12 ; R=0.37 ; P>0.15$ (not shown)).

Solid circle $=0 \mathrm{mg} / \mathrm{kg}$, solid triangle $=1 \mathrm{mg} / \mathrm{kg}$.

In the current study, a threshold for residual liver iron, which reflects iron storage, was identified below which brain iron was compromised while erythropoiesis was not. Brain iron was relatively conserved until liver iron was depleted to $\sim 10 \%$ of that observed in non-phlebotomized controls. Autopsy findings in a study in term iron-deficient human neonates demonstrated a similar brain iron threshold at $10 \%$ residual liver iron (13). We were gratified to achieve a similar threshold response in our lamb model as in the human neonate. The threshold at which competition for iron between RBCs and the brain likely varies among species, dictated by the iron demand of the competing physiologic processes of brain development and erythropoiesis. For example, initial hemoglobin concentrations targeted in the lambs after saline exchange transfusion represented a $\geq 40 \%$ reduction in the total RBC volume. Despite these significant phlebotomy losses, only the most severely iron depleted animals in negative iron balance demonstrated competition for iron between the brain and the RBCs. Lambs in less negative or in positive iron balance were less affected and iron distribution to the brain and to the RBCs were preserved at the

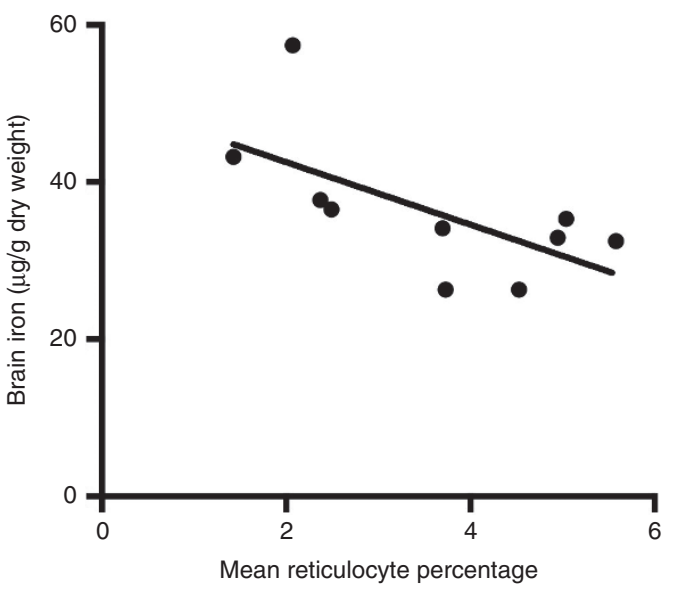

Figure 6. Brain iron concentration as a function of mean reticulocytes (\%) in the peripheral blood of animals in negative iron balance with no iron supplementation $(R=0.55, P<0.05)$. Solid circle $=0 \mathrm{mg} / \mathrm{kg}$.

expense of the liver. On the other hand, human neonates present a unique challenge to maintaining iron balance because they have larger, more metabolically active brains relative to the lamb and to other model species $(29,31)$. The high metabolic demand of the human infant brain makes it more vulnerable to small changes in substrate (e.g., iron) availability. Lambs, whose brain metabolic rate is only $1.7 \%$ of total oxygen consumption (32), would not be expected to have the same sensitivity to modest changes in iron availability. We utilized these considerations in designing the amount of phlebotomy and the amount of iron supplementation in this study.

It is important to note that brain iron deficiency as a result of PIA in the very preterm infant has not yet been definitively demonstrated. Previously discussed data from other at-risk populations such as growth-restricted infants or infants born to diabetic mothers suggest that the very preterm or critically ill infants may also be at risk for brain iron deficiency due to their high phlebotomy losses and risk of a rapidly accumulating iron deficit. It is the impact of multiple factors on the total body iron balance that ultimately confers risk to preterm infants. Iron balance is supported by iron supplementation and blood transfusion-practices that can vary greatly in clinical practice. As an example, the American Academy of Pediatrics recommends iron supplementation of $2 \mathrm{mg} / \mathrm{kg} / \mathrm{d}$ provided enterally by $4 \mathrm{wk}$ of age in stable premature infants (33). However, enteral iron has variable absorption in preterm infants, potentially as low as $7 \%$, but up to $30-40 \%$ on average (34). In our study, $2 \mathrm{mg} / \mathrm{kg} / \mathrm{d}$ of i.v. iron supplementation achieved a net neutral iron balance in phlebotomized lambs. If this adjusted for enteral dosing with an average absorption rate of $30 \%, \sim 6 \mathrm{mg} / \mathrm{kg} / \mathrm{d}$ enteral iron would be needed to maintain a net neutral iron balance with ongoing phlebotomy. Likewise, an enteral iron dose of $15 \mathrm{mg} / \mathrm{kg} / \mathrm{d}$ would be needed to achieve a net positive iron balance in the critically ill infant with ongoing phlebotomy losses based on our study findings. Therefore, it is possible that the average recommended enteral iron supplementation dose of $2 \mathrm{mg} / \mathrm{kg} / \mathrm{d}$ may be inadequate in the high-risk infant 


\section{Articles | zamora et al.}

to either replace a whole body iron deficit or even maintain a neutral iron balance.

The risk of neonatal brain iron deficiency due to repeated phlebotomy is real; preterm and critically ill term infants regularly undergo small volume phlebotomy for laboratory analysis, which can add up to their entire blood volume every $2 \mathrm{wk}$ (1). Since the majority of neonatal iron resides in the RBC mass (35), each gram of hemoglobin removed by phlebotomy represents a loss of $3.46 \mathrm{mg}$ of elemental iron from the total body pool. In addition, these at-risk infants have limited iron stores, rapid growth rates, and a continual need for an expanding blood volume. Two commonly employed therapies, nutritional iron supplementation and RBC transfusion, may counteract the negative iron balance induced by phlebotomy by supplying additional iron. Significant controversy persists surrounding optimal timing, dose, and route of supplemental iron administration in preterm infants due to its potential risk for increased oxidative stress (36). Currently, iron supplementation practices vary, both nationally and internationally $(11,36)$. RBC transfusions are given to replace blood lost through phlebotomy with the concurrent benefit of replacing iron that is lost as well. However, more restrictive blood transfusion practices have evolved $(7,8,37)$ because of increased concerns regarding the potential toxicity of blood transfusions. Negative iron balance generally occurs because the amount of iron given by either route is less than the growing total body iron deficit and the ongoing demand to support erythropoiesis, ex-utero growth, and brain development.

The detection of brain iron deficiency in clinical practice remains problematic, particularly in the preanemic state. To date, the assumption has been that the iron status of the brain is reflected by biomarkers obtained from the peripheral blood such as markers of reticulocytosis and erythroid iron status. However, this study provides evidence that the prioritization or utilization of iron in the RBC mass does not always occur in parallel with the brain. Human neonates and infants can have brain iron deficiency and neurobehavioral alterations in the absence of anemia $(17,38)$. Serum ferritin is sometimes used as a surrogate marker of brain iron deficiency. Although falling ferritin levels do not directly correlate with brain iron status, they may predict the risk of brain iron deficiency. Ferritin concentrations of $<40 \mu \mathrm{g} / \mathrm{l}$ in humans have been shown to correlate with the "threshold" at which brain iron is affected $(13,17)$, although affected learning and memory have been demonstrated in cord blood ferritins of $<76 \mu \mathrm{g} / \mathrm{l}$ (39).

Since there is a hierarchical progression to tissue level iron division, biomarkers that predate brain iron deficiency are needed. In our study, the mean TIBC saturation was significantly lower at $10 \mathrm{~d}$ of age in the animals in negative iron balance $(\leq 2.1 \%$, see Table 1$)$ compared to those animals in net neutral or net positive iron balance, serving as a possible indicator of impending brain iron deficiency. Additional research should focus on how to best identify infants at risk for brain iron deficiency, and how best to mitigate these risks so that neurodevelopmental outcomes can be optimized. Further research is needed to fully understand the impact of iron prioritization away from the brain during neonatal anemia on functional outcomes such as neurobehavioral development.

\section{Conclusion}

Iron was prioritized to $\mathrm{RBC}$ production over brain accretion in a model of PIA in neonatal lambs. This has relevance to the neonatal intensive care unit, where critically ill preterm and term neonates undergo extensive iron loss through phlebotomy for frequent laboratory analysis. The risk to the neonate is further accentuated by the lack of a specific laboratory indicator of brain iron status. This problem is of high clinical importance because early life iron deficiency leads to persistent learning and memory deficits because of iron-dependent critical periods found in early brain development. Based on the principle of iron prioritization as demonstrated in this study, limiting unnecessary blood draws, optimizing iron supplementation, and considering the impact of blood transfusions on the total body iron status may be clinically important considerations to support iron balance in the high risk neonate and improve their long-term outcomes.

\section{METHODS}

The University of Iowa's Animal Care and Use Review Committee reviewed and approved this study. Additional details of the experimental study design, materials, and methods in these same animals have been previously published in a study focused on the inter- and intra-organ distribution of iron in this model of PIA (40). This study represents the specific assessment of iron prioritization between the RBC mass and the developing brain.

\section{Experimental Protocol}

At 2 to $3 \mathrm{~d}$ of age, 10 neonatal twin lamb pairs were randomized in which 1 twin received i.v. iron supplementation, and its twin received no iron supplementation. Within the iron supplementation group, lambs received an average daily dose of elemental iron of $1 \mathrm{mg} / \mathrm{kg}$ $(n=3), 2 \mathrm{mg} / \mathrm{kg}(n=3)$, or $5 \mathrm{mg} / \mathrm{kg}(n=3)$. An additional lamb received $15 \mathrm{mg} / \mathrm{kg} / \mathrm{d}$ of i.v. iron supplementation but was not included in the final analysis given the small size of the sample group $(n=1)$. Within 2-3 d of birth, a percutaneous jugular venous catheter was placed, and animals underwent exchange transfusion with normal saline, acutely dropping the hemoglobin to a target value of $60 \mathrm{~g} / \mathrm{l}$, decreasing the RBC mass by $40 \%$. Over the subsequent 11 -d period, the lambs were phlebotomized at $6-9 \mathrm{ml} / \mathrm{kg}$ body weight at six additional times occurring every other day. The iron-supplemented lambs received their first i.v. iron dose immediately after the exchange transfusion, and following each subsequent phlebotomy. A non-phlebotomized control group consisted of 5 lambs that received $3 \mathrm{mg} / \mathrm{kg}$ i.v. iron supplementation daily. Serum hemoglobin, reticulocyte count, plasma iron, and TIBC were monitored at least daily in all lambs prior to and throughout the phlebotomy period. Sacrifice was by overdose of phenobarbital sodium. The organs were weighed, samples collected, and frozen at $-70^{\circ} \mathrm{C}$ for later analysis.

\section{Biochemical and Hematological Methods}

Tissue iron concentration was determined on thawed tissue samples rinsed with normal saline. The samples were lyophilized for $72 \mathrm{~h}$, then weighed and digested by a $10 \mathrm{ml}$ solution of $4: 170 \%$ nitric acid: $70 \%$ perchloric acid. Tissue iron concentrations were determined by atomic absorption spectroscopy and compared to standard solutions, as previously described (16).

Hemoglobin concentrations were determined using an IL-482 CO-Oximeter (Instrumentation Laboratories, Lexington, MA). Reticulocyte count was determined using a bench top flow cytometer (FACScan; Becton-Dickinson, San Jose, CA), stained with thiazoleorange (Retic-COUNT, Becton-Dickinson) and analyzed with ReticCOUNT software, version 1.0 (Becton-Dickinson). Plasma iron and 
TIBC were assessed in duplicate electrochemically with a Ferrochem II Analyzer (ESA, Bedford, MA). The interassay variability was $<5 \%$.

\section{Data Management}

Net iron balance, individual tissue iron content, and the RBC iron content were calculated. Tissue iron contents of the liver, brain, heart, and skeletal muscle were determined as the product of the measured tissue iron concentration per dry weight and the wet to dry ratio of the specific tissue and the organ weight. For example, the brain iron concentration was measured, and multiplied by $8.3: 1$, the wet to dry ratio of the brain tissue and the brain weight. The RBC iron content was calculated from an estimated blood volume of $80 \mathrm{ml} / \mathrm{kg}$ body weight, $3.47 \mathrm{mg}$ of elemental iron/gram of hemoglobin, the hemoglobin concentration, and animal weight at time of sacrifice. The magnitude of the blood loss in the study is accounted for in the net iron balance calculation. The net iron balance over the experimental period was determined by subtracting the milligram of iron in hemoglobin removed by phlebotomy from the i.v. iron administered in $\mathrm{mg} / \mathrm{kg} / \mathrm{d}$.

\section{Data Analysis}

Net iron balance was compared among the iron dosage groups. Iron prioritization was assessed by first determining the total measured iron content from each lamb in three major tissue compartments: storage iron (liver), erythroid iron (RBC mass), and metabolically active and functionally important nonstorage, nonerythroid iron (brain, heart, skeletal muscle). The details of these analyses have been previously described (40). Iron prioritization was determined as the percentage of measured iron content of each tissue compartment or organ as a function of the total measured iron content of the RBCs, liver, brain, heart, and skeletal muscle combined. The effect of iron balance on the percentage of total iron allocated to a given organ was assessed by regression analysis, as was the relationship between brain iron concentration and liver iron concentration. In order to assess iron prioritization between RBCs and brain, brain iron concentration was plotted as a function of the percent of total measured iron allocated to the RBCs and as a function of the mean reticulocyte count from the 11-d sampling period. Both relationships were assessed by regression analysis. All data were parametric. Statistical significance for all comparisons was set at an $\alpha$ of 0.05 .

\section{ACKNOWLEDGMENT}

We acknowledge Robert L. Schmidt, Barbara Stewart, and Kathy Byers at the University of lowa and Jane Wobken at the University of Minnesota for their technical assistance.

\section{STATEMENT OF FINANCIAL SUPPORT}

This study was supported by National Heart, Lung, and Blood Institute Grant P01-HL046975, Bethesda, Maryland, USA; National Institute of Child Health and Human Development Grant R01-HD-29421, Bethesda, Maryland, USA; and Children's Miracle Network Telethon, Salt Lake City, Utah, USA.

Disclosure: None.

\section{REFERENCES}

1. Widness JA. Pathophysiology of anemia during the neonatal period, including anemia of prematurity. Neoreviews 2008;9:e520.

2. DeBoer T, Wewerka S, Bauer PJ, Georgieff MK, Nelson CA. Explicit memory performance in infants of diabetic mothers at 1 year of age. Dev Med Child Neurol 2005;47:525-31.

3. Amin SB, Orlando M, Eddins A, MacDonald M, Monczynski C, Wang H. In utero iron status and auditory neural maturation in premature infants as evaluated by auditory brainstem response. J Pediatr 2010;156: $377-81$.

4. Felt BT, Lozoff B. Brain iron and behavior of rats are not normalized by treatment of iron deficiency anemia during early development. J Nutr 1996;126:693-701.

5. McEchron MD, Cheng AY, Liu H, Connor JR, Gilmartin MR. Perinatal nutritional iron deficiency permanently impairs hippocampus-dependent trace fear conditioning in rats. Nutr Neurosci 2005;8:195-206.

6. Ortiz E, Pasquini JM, Thompson K, et al. Effect of manipulation of iron storage, transport, or availability on myelin composition and brain iron content in three different animal models. J Neurosci Res 2004;77:681-9.
7. Kirpalani H, Whyte RK, Andersen C, et al. The premature infants in need of transfusion (PINT) study: a randomized, controlled trial of a restrictive (low) versus liberal (high) transfusion threshold for extremely low birth weight infants. J Pediatr 2006;149:301-7.

8. Bell EF, Strauss RG, Widness JA, et al. Randomized trial of liberal versus restrictive guidelines for red blood cell transfusion in preterm infants. Pediatrics 2005;115:1685-91.

9. McCoy TE, Conrad AL, Richman LC, Lindgren SD, Nopoulos PC, Bell EF. Neurocognitive profiles of preterm infants randomly assigned to lower or higher hematocrit thresholds for transfusion. Child Neuropsychol 2011;17:347-67.

10. Whyte RK, Kirpalani H, Asztalos EV, et al.; PINTOS Study Group. Neurodevelopmental outcome of extremely low birth weight infants randomly assigned to restrictive or liberal hemoglobin thresholds for blood transfusion. Pediatrics 2009;123:207-13.

11. Guillén U, Cummings JJ, Bell EF, et al. International survey of transfusion practices for extremely premature infants. Semin Perinatol 2012;36:244-7.

12. Urrechaga E, Borque L, Escanero JF. Biomarkers of hypochromia: the contemporary assessment of iron status and erythropoiesis. Biomed Res Int 2013;2013:603786.

13. Petry CD, Eaton MA, Wobken JD, Mills MM, Johnson DE, Georgieff MK. Iron deficiency of liver, heart, and brain in newborn infants of diabetic mothers. J Pediatr 1992;121:109-14.

14. Georgieff MK, Petry CD, Wobken JD, Oyer CE. Liver and brain iron deficiency in newborn infants with bilateral renal agenesis (Potter's syndrome). Pediatr Pathol Lab Med 1996;16:509-19.

15. Kuzawa CW. Fetal origins of developmental plasticity: are fetal cues reliable predictors of future nutritional environments? Am J Hum Biol 2005; 17:5-21.

16. Fretham SJ, Carlson ES, Georgieff MK. The role of iron in learning and memory. Adv Nutr 2011;2:112-21.

17. Siddappa AM, Georgieff MK, Wewerka S, Worwa C, Nelson CA, Deregnier RA. Iron deficiency alters auditory recognition memory in newborn infants of diabetic mothers. Pediatr Res 2004;55:1034-41.

18. Connor JR, Menzies SL, St Martin SM, Mufson EJ. Cellular distribution of transferrin, ferritin, and iron in normal and aged human brains. J Neurosci Res 1990;27:595-611.

19. Georgieff MK, Schmidt RL, Mills MM, Radmer WJ, Widness JA. Fetal iron and cytochrome $\mathrm{c}$ status after intrauterine hypoxemia and erythropoietin administration. Am J Physiol 1992;262:R485-91.

20. de Deungria M, Rao R, Wobken JD, Luciana M, Nelson CA, Georgieff MK. Perinatal iron deficiency decreases cytochrome $\mathrm{c}$ oxidase (CytOx) activity in selected regions of neonatal rat brain. Pediatr Res 2000;48:169-76.

21. Mash DC, Pablo J, Flynn DD, Efange SM, Weiner WJ. Characterization and distribution of transferrin receptors in the rat brain. J Neurochem 1990;55:1972-9.

22. Moos T, Morgan EH. Transferrin and transferrin receptor function in brain barrier systems. Cell Mol Neurobiol 2000;20:77-95.

23. Taylor EM, Morgan EH. Developmental changes in transferrin and iron uptake by the brain in the rat. Brain Res Dev Brain Res 1990;55:35-42.

24. Siddappa AJ, Rao RB, Wobken JD, Leibold EA, Connor JR, Georgieff MK. Developmental changes in the expression of iron regulatory proteins and iron transport proteins in the perinatal rat brain. J Neurosci Res 2002;68:761-75.

25. Cheah JH, Kim SF, Hester LD, et al. NMDA receptor-nitric oxide transmission mediates neuronal iron homeostasis via the GTPase Dexras1. Neuron 2006;51:431-40.

26. Erecinska M, Cherian S, Silver IA. Energy metabolism in mammalian brain during development. Prog Neurobiol 2004;73:397-445.

27. Fretham SJ, Carlson ES, Wobken J, Tran PV, Petryk A, Georgieff MK. Temporal manipulation of transferrin-receptor-1-dependent iron uptake identifies a sensitive period in mouse hippocampal neurodevelopment. Hippocampus 2012;22:1691-702.

28. Guiang SF 3rd, Widness JA, Flanagan KB, Schmidt RL, Radmer WJ, Georgieff MK. The relationship between fetal arterial oxygen saturation and heart and skeletal muscle myoglobin concentrations in the ovine fetus. J Dev Physiol 1993;19:99-104.

29. Fretham SJ, Carlson ES, Georgieff MK. Neuronal-specific iron deficiency dysregulates mammalian target of rapamycin signaling during 


\section{Articles | zamora et al.}

hippocampal development in nonanemic genetic mouse models. J Nutr 2013;143:260-6.

30. Carlson ES, Stead JD, Neal CR, Petryk A, Georgieff MK. Perinatal iron deficiency results in altered developmental expression of genes mediating energy metabolism and neuronal morphogenesis in hippocampus. Hippocampus 2007;17:679-91.

31. Leonard WR, Robertson ML, Snodgrass JJ, Kuzawa CW. Metabolic correlates of hominid brain evolution. Comp Biochem Physiol A Mol Integr Physiol 2003;136:5-15.

32. Kuzawa CW. Adipose tissue in human infancy and childhood: an evolutionary perspective. Am J Phys Anthropol 1998;Suppl 27:177-209.

33. Iron fortification of infant formulas. American Academy of Pediatrics. Committee on Nutrition. Pediatrics 1999;104:119-23.

34. Fomon SJ, Nelson SE, Ziegler EE. Retention of iron by infants. Annu Rev Nutr 2000;20:273-90.
35. Oski FA. Iron deficiency in infancy and childhood. N Engl J Med 1993;329:190-3.

36. Mills RJ, Davies MW. Enteral iron supplementation in preterm and low birth weight infants. Cochrane Database Syst Rev 2012;3:CD005095.

37. Widness JA, Seward VJ, Kromer IJ, Burmeister LF, Bell EF, Strauss RG. Changing patterns of red blood cell transfusion in very low birth weight infants. J Pediatr 1996;129:680-7.

38. Shafir T, Angulo-Barroso R, Jing Y, Angelilli ML, Jacobson SW, Lozoff B. Iron deficiency and infant motor development. Early Hum Dev 2008;84:479-85.

39. Tamura T, Goldenberg RL, Hou J, et al. Cord serum ferritin concentrations and mental and psychomotor development of children at five years of age. J Pediatr 2002;140:165-70.

40. Guiang SF 3rd, Georgieff MK, Lambert DJ, Schmidt RL, Widness JA. Intravenous iron supplementation effect on tissue iron and hemoproteins in chronically phlebotomized lambs. Am J Physiol 1997;273:R2124-31. 